\title{
Sobre la necesidad de Filosofía contextual. Dussel y Roig, dos contribuciones para pensar el presente del filosofar latinoamericano
}

On the need for contextual philosophy. Dussel and Roig, two contributions to think about the present of Latin American philosophizing

José Ernesto Bianchi

Universidad Nacional de Cuyo - Argentina

Mendoza, Argentina

joseernestobianchi@hotmail.com

Nadia Jimena Irrazabal Astudillo

Universidad Nacional De Cuyo - Argentina

Mendoza, Argentina

irrazabal_nadia@hotmail.com

\section{RESUMEN}

En este trabajo nos proponemos desarrollar dos visiones acerca del quehacer filosófico a partir del análisis de los trabajos de Enrique Dussel y Arturo Roig. Realizaremos un análisis hermenéutico sobre la constitución formal del discurso filosófico en estos autores, tomando como referencia dos textos centrales de Enrique Dussel y Arturo Roig, poniendo principal atención en cómo operan desde la crítica que realizan al eurocentrismo filosófico moderno, hacia una definición del fundamento mismo del acto de filosofar. Abordando estas obras desde el análisis de discurso filosófico, mixturado con elementos específicos de la Historia de Ideas, analizaremos las características del pensamiento filosófico hegemónico que buscan combatir y los supuestos que lo sostienen, señalando sus fracturas doctrinales y axiológicas, para luego ofrecer una posibilidad afirmativa frente al presente y al porvenir del filosofar latinoamericano. Finalmente, con el objeto de dar algo de luz sobre este problema general que abre el trabajo ¿Para qué una filosofía latinoamericana?, extraeremos algunas conclusiones sobre lo que deba ser nuestro filosofar, direccionadas en el sentido de abandonar la dicotomía entre teoría y praxis, como así también la prerrogativa aristotélica de la filosofía como un saber inútil y desafectado de su contexto.

Palabras Clave: Dussel; Roig; Filosofía Latinoamericana; Filosofía de la Liberación; Historia de la Ideas. 
In this paper, we propose to develop two visions of philosophical work based on the analysis of the works of Enrique Dussel and Arturo Roig. We will carry out a hermeneutic analysis of the formal constitution of philosophical discourse in these authors, taking as reference two central texts by Enrique Dussel and Arturo Roig, paying special attention to how they operate from their critique of modern philosophical Eurocentrism towards a definition of the very foundation of the act of philosophizing. Approaching these works from the analysis of philosophical discourse, mixed with specific elements of the History of Ideas, we will analyze the characteristics of the hegemonic philosophical thought they seek to combat and the assumptions that sustain it, pointing out its doctrinal and axiological fractures, in order to then offer an affirmative possibility for the present and the future of Latin American philosophizing. Finally, with the purpose of shedding some light on this general problem that opens the work, we will draw some conclusions on what our philosophizing should be, directed in the sense of abandoning the dichotomy between theory and praxis, as well as the Aristotelian prerogative of philosophy as useless knowledge, disaffected from its context.

Keywords: Dussel; Roig; Latin American Philosophy; Philosophy of Liberation; History of Ideas.

\section{Introducción}

La Filosofía Latinoamericana carga desde sus albores la cruz de tener que justificarse a sí misma, dar cuenta de su razón de ser, no solo en el sentido de su indispensabilidad sociopolítica, sino también por el rango ontológico de su existencia. Este debate, ya a nuestros ojos perogrullesco y superado, ha atravesado diversísimas variantes, de las cuales la más difundida, más no la única, es la pretendida controversia de los años sesenta entre Augusto Salazar Bondy y Leopoldo Zea. La misma, versa en torno a la condición de posibilidad de una Filosofía vernácula, sus características y sus fines.

Mientras que el análisis de Salazar Bondy le da especial preeminencia al factor de la dependencia económica y la toma de conciencia acerca de la misma como factor central para propiciar un despertar del pensamiento filosófico latinoamericano, Zea propone que el solo hecho de pensarnos en nuestra circunstancia concreta y con atención a nuestros problemas, ya sea con caja de herramientas propia o ajena, comporta en sí mismo un ejercicio filosófico auténtico. Al respecto nos dice Arpini:

... del polémico texto de Augusto Salazar Bondy cuyo título inquiría sobre la existencia de una Filosofía auténtica y original de Nuestra América. Dicho texto dio lugar a un importante debate entre cuyos contendientes se encontraba Leopoldo Zea, quien sostuvo que una filosofía auténtica es aquella que reflexiona "sin más" a partir de su propia realidad (Arpini, 2018, p. 34). 
Vemos claramente como en ambas perspectivas, que como se ha mostrado con insistencia no son necesariamente excluyentes, de lo que se trata es de justificarse a sí mismo en torno al rigor ontológico del filosofar latinoamericano, pero siempre suponiendo la necesidad de que una Filosofía propia se extienda y prolifere entre nosotros. Es decir, la importancia y la necesidad de cultivar la Filosofía en nuestras latitudes se da ya por sentada.

No queremos con esta mención pasar por iconoclastas o "ultracriticistas", nada más lejos de nuestras pretensiones, sino simplemente mostrar la inquietud que nos lleva a pensar nuevamente quizás de forma excesivamente cándida o pretenciosa, este problema. Tiene que ver pues con esa suposición o mandato de "tener que tener nuestra filosofía". Y aunque la nuestra es en principio una inquietud de carácter netamente nominal implica, según creemos, consecuencias éticas importantes. Surge en parte de la observación sencilla en torno al modo en el cual se incluyen solidaria y hasta exóticamente en los actuales congresos internacionales de Filosofía a las variedades culturales del pensamiento a partir del uso del genitivo aplicado a la Filosofía, entonces se encuentran, por ejemplo, filosofías de oriente, filosofías africanas, filosofías del sur, y así un largo etcétera.

Entonces, si pensamos que la narrativa que conocemos como "Filosofía" (no así el pensamiento, la reflexión y la razón crítica, obviamente), surge en un determinado contexto y bajo determinadas reglas y supuestos bien específicos, ¿por qué la necesidad de llamar entonces a nuestra reflexión sobre nosotros mismos "Filosofía"?, ¿qué dignidad otorga este modo de saber o disciplina a nuestras meditaciones, que necesitamos nombrarlas y encasillarlas bajo este molde? $\mathrm{O}$ mejor aún, si sabemos en nuestros tiempos que el pensamiento universalizante o totalitario que funda y dirige la historia occidental es por su misma naturaleza encubridor y excluyente, ¿por qué la necesidad de perpetuarlo, bajo formas más o menos críticas de esa universalidad y no directamente rebautizar el ejercicio del pensar bajo otras prerrogativas?

Estos últimos cuestionamientos vienen a cuento de que la Filosofía Latinoamericana se ha diferenciado notablemente por su objeto y sus fines de la tradicional forma del filosofar europeo. Sin desconocer el hecho de que la consolidación del eurocentrismo implica un largo proceso histórico que naturalmente excede los límites del objeto de este trabajo, trataremos de caracterizar el modo de ser general del mismo, mencionando dos figuras constituyentes de sus momentos augural y crepuscular. De este modo, el pensar filosófico europeo, como disciplina particular y con específicas pretensiones epistemológicas surge como tal, según el consenso común de los especialistas y sin negar sus fuentes e influencias orientales que ya reconocía el propio Platón, en el siglo VII a.C. en la región mediterránea de Jonia, y queda definitivamente ordenado a través de la figura de Parménides (s. V a.C.), que le imprime para siempre el sello de un pensar independiente de toda determinación ajena y que puede dar cuenta de sí mismo. Muestran esta dirección sentencias tales como: "el Ser es, el No Ser no es" (Parménides, 1984, 49) y sobre todo "lo mismo es el pensar y aquello por lo que hay pensamiento" (Parménides, 1984, 50), pertenecientes ambas a su poema Sobre la Naturaleza. Lo digno de ser pensado desde esta Filosofía es entonces lo único, indivisible, inmutable, inmóvil e intemporal, negando así todo lo que posea algún atisbo de No Ser, es decir de cambio, puesto que la razón filosófica no podría admitir la contradicción de que la Verdad sea y no sea a la vez. Por ello, no pueden darse como objeto de estudio de tal filosofar temas como la política, la literatura, los saberes populares y 
demás expresiones propias de la historia de los pueblos, localizadas en un lugar y un tiempo específicos y determinadas inherentemente por el devenir.

Así mismo y culminando esta línea ideológica nos encontramos con la figura del pensador alemán George Wilhelm Friedrich Hegel, quien viene a reiterar esta dirección para la Filosofía, pero ahora con el ánimo de subsumir su historia bajo el modelo de un proceso racional y necesario. Nos dice en su Introducción a la Historia de la Filosofía, que la Filosofía como único modo posible del pensamiento libre debe rehuir de determinaciones ajenas al mismo pensamiento, puesto que la falta de libertad consiste justamente en el hecho de ser en otra cosa. Por tanto, el pensamiento libre es el que se piensa a sí mismo, siendo en sí y para sí. Historia de la Filosofía es para Hegel entonces la historia del pensamiento, o más precisamente de lo universal:

En la Historia se nos presenta todo aquello que es mudable, lo que ha ocurrido, lo que ha sido, lo que ha caído en la noche de los tiempos, lo que ya no existe. Pero el pensamiento no es susceptible de ningún cambio; no ha existido ni ha pasado, sino que es (Hegel, 1961, p. 33).

Vemos muy claramente en estos dos hitos del filosofar occidental europeizante cómo en torno a la consideración de la Filosofía se tiene por condición de posibilidad un pensar inminentemente desafectado de la Historia. No hace falta denotar que lo que para el pensar latinoamericano es una virtud y a su vez el principio de su misión y desarrollo como un pensar desde una situación y para las necesidades, en la disciplina llamada Filosofía y desarrollada desde Europa se ve en tal compromiso una imposibilidad epistemológica. Entonces, ¿por qué seguir llamando "Filosofía" a este pensar nuestro que se emancipó de esa necesidad de pensar sobre lo Mismo?

Ahora bien, en razón de estas elucubraciones iniciales, que más por su vaguedad que por su presunción, no son merecedoras de una respuesta cerrada y concluyente, quisimos hacer lugar aquí para el ejercicio de pensar el problema de la delimitación y la definición de la Filosofía Latinoamericana, específicamente en los trabajos de dos autores que forjaron y encauzaron esta línea de pensamiento, Arturo Roig y Enrique Dussel, para así acercarnos un poco a la claridad de saber de qué hablamos cuando hablamos de Filosofía en nuestros contextos. Por otro lado, intentaremos observar algunas cuestiones propias de la definición que, de la Filosofía, dé cada pensador, para contrastarlas y arribar a una reflexión propia acerca del asunto.

En este sentido, y luego de la mencionada disputación paradigmática entre Salazar Bondy y Zea sobre la naturaleza y razón de ser de la Filosofía Latinoamericana, mucho y en muchos sentidos se ha escrito. En nuestro caso queremos ofrecer ahora una muy breve revisión de algunos de estos importantes aportes, siempre en clave de análisis de las obras de Roig y Dussel a este respecto de definir y justificar la necesidad de una Filosofía propia, para posicionar esta investigación en una determinada línea de trabajo que facilite así su inteligencia. Existen entre las publicaciones más recientes sobre este tema, por lo menos dos grandes compilaciones importantes al respecto de las obras de los autores que ponemos en diálogo en este trabajo, de allí habremos de considerar el estado de la cuestión en un sentido general y el lugar de nuestra investigación. 
Por un lado, sobre la contribución del pensamiento de Roig a la filosofía latinoamericana, hay un muy representativo libro editado en el 2020 por Adriana Arpini, Marisa Muñoz y Dante Ramaglia, Diálogos Inacabados con Roig, Filosofía Latinoamericana, Historia de las Ideas y Universidad, donde se compilan colaboraciones de grandes referentes del pensamiento latinoamericano, sobre el trabajo intelectual de Arturo Roig, a través de cuatro ejes temáticos generales: Filosofía y Pensamiento Latinoamericano, Historia de la Ideas y expresiones culturales de Nuestra América, Universidad y Pedagogía, Testimonios y Entrevistas. Así, más allá de la riqueza de estos tópicos, nos concentraremos en el primero que compete decisivamente a nuestro trabajo. En el mismo contamos con los estudios sobre la posición filosófica de Roig donados por Yamandú Acosta, Gerardo Oviedo y Dante Ramaglia que dan una visión bastante precisa de este asunto.

Yamandú Acosta nos habla de la obra de Roig como "Humanismo crítico desde nuestra América" (Acosta, 2020, p. 25), situándolo de esta forma en la tradición fundada por Martí, haciendo especial hincapié en el análisis del a priori antropológico, como condición de posibilidad de una filosofía auroral, categoría que tomaremos en este trabajo como parte de nuestro desarrollo de los puntos de partida constitutivos del discurso filosófico en Roig. Siguiendo esta línea de trabajo fundada en el desarrollo de las categorías del a priori antropológico y la Filosofía como saber auroral, Gerardo Oviedo describe la propuesta roigiana como una agonística de la emergencia (Oviedo, 2020, p. 71), haciendo foco en las tensiones ideológicas que atraviesan todo discurso y la misión de nuestra filosofía de desenmascarar esos trasfondos, denunciando la injusticia presente y proyectando utópicamente un porvenir que nos dirija hacia lo nuevo propio como distinto de lo sido extraño.

Dante Ramaglia por su parte despliega un itinerario intelectual de gran interés para comprender el orden de desarrollo de los principales aportes de Roig a la Filosofía Latinoamericana, de los cuales nos interesa especialmente la ampliación metodológica introducida por Roig frente a los típicos textos canónicos de interés filosófico (Ramaglia, 2020, p. 51), cuestión también sugerida por Oviedo cuando comenta la lectura emancipatoria que hace Roig de Antígona (Oviedo, 2020, p. 75). Existen pues múltiples fuentes desde la cuales la Filosofía puede extraer contenido que nos hable de las tensiones vigentes de nuestra época. En este sentido recurriremos a esta idea para mostrar una de las diferencias fundamentales entre las propuestas de la Historia de las ideas de Arturo Roig y la Filosofía de la Liberación de Enrique Dussel.

Dussel, por su parte, es un autor que también ha generado grandes sucesiones de disputas y ponderaciones con sus siempre movilizantes escritos. En este caso tomaremos un valiosísimo libro del 2018, Del Monólogo europeo al diálogo interfilosófico, coordinado por José Guadalupe Gandarilla Salgado y Mabel Moraña, que compila participaciones notables acerca de su obra en sus múltiples facetas: Filosófica, Ética, Política, Económica, Geo-política e Histórica. Si bien en sus trabajos estas distinciones no son excluyentes sino complementarias, nos detendremos en el breve comentario de aquellos estudios volcados a describir su labor filosófica.

En el primero la Dra. Adriana Arpini, hace una recuperación de su biografía intelectual para mostrar el importante paso que ejerce el pensamiento dusseliano en su etapa previa al exilio, al ampliar su visión acerca de la misión del filósofo: de considerarlo un mero mediador entre el pueblo y el político, hasta posicionarlo como intelectual crítico y comprometido, que toma 
como punto de partida de su valoración la voz del oprimido (Arpini, 2018, p. 31). Vemos en el texto de Arpini una preocupación por determinar el lugar político que debe ocupar la Filosofía en los textos de las dos etapas de Dussel, más no una determinación formal de este saber, que es lo que a nosotros nos interesa para confrontarlo con la posición de Arturo Roig.

Por su parte Scannone, en este mismo libro, plantea una historia, caracterización y vigencia del programa filosófico de la Filosofía de la Liberación, movimiento de ideas que cuenta a Enrique Dussel como figura central de sus momentos fundacional, crítico y de divulgación. En este estudio de mucho interés para la interpretación y materialización actual de estas ideas acerca de la Filosofía, se presenta una descripción de sus rasgos esenciales en razón de su posición ante los problemas que la invocan. Así se afirma esta Filosofía como una praxis de liberación, situada (concreta, histórica y aculturada), que toma como punto de partida la exterioridad del otro y tiene como tarea fundamental una relectura en clave crítica de la Historia de la Filosofía (Scannone, 2018, p. 41). En este sentido, Scannone realiza una descripción fenomenológica de este modo de saber, pero no de su configuración discursiva formal, como pretendemos en este trabajo.

En este mismo nivel de análisis, pero desde la óptica política y ética, Pablo Guadarrama González define la labor intelectual de Dussel como un Humanismo práctico, inserto en una específica y rica tradición latinoamericana (Guadarrama González, 2018, p. 58), de las características descriptas con anterioridad, y que tiene como principal objeto salvar la dignidad del oprimido (Guadarrama González, 2018, p. 70). Los trabajos de Alcoff (Alcoff, 2018) y Guardiola Rivera (Guardiola Rivera, 2018), con su indiscutible valor, continúan desarrollando este tipo de descripciones, pero sin ofrecer una línea de interpretación estructural del discurso filosófico.

Por nuestra parte, como habíamos adelantado, nos proponemos en principio analizar dos visiones particulares acerca del quehacer filosófico latinoamericano desde su planteo discursivo formal: la de Enrique Dussel en su artículo Una nueva edad para la historia de la Filosofía y la de Arturo Roig en la introducción de su obra capital Teoría y Crítica del Pensamiento Latinoamericano. Conscientes del riesgo de que toda selección conlleva una injusticia, optamos por este criterio excluyente y parcial, no solo guiados por la prudencia de no querer agotar en este pequeño aporte la multitud de visiones que se vienen sucediendo desde el despertar de nuestra conciencia filosófica acerca de esta problemática y sus aristas, sino también porque consideramos que el prestigio y reconocimiento del que gozan las propuestas de estos autores en la comunidad científica regional y su lugar preponderante en la fundación y promoción de dos de las principales corrientes críticas de pensamiento de nuestra era, la Filosofía de la Liberación y la Historia de las ideas, hablan por sí mismos de la no arbitrariedad de la selección.

\section{Metodología}

Para realizar esta revisión conceptual comparativa entre Dussel y Roig, nos serviremos metodológicamente del análisis del discurso filosófico, al modo de una confrontación exegética con los textos aludidos, para localizar en ellos las principales ideas en torno a la definición del fundamento y peculiaridad del saber filosófico. Así finalmente recurrimos a ciertos elementos interpretativos de la Historia de las ideas, tales como la consideración del lenguaje como hecho histórico que trasluce los modos de ser de una sociedad, en el marco de la conformación 
inherentemente conflictiva de un universo discursivo. Esto nos funcionará para posicionar políticamente estas conceptualizaciones propuestas por Dussel y Roig en la tensión con los planteos típicamente eurocéntricos, atendiendo a los intereses políticos implícitos que operan en cada caso.

En razón del recorte bibliográfico, diremos que en los textos seleccionados se expone debidamente el planteamiento general de estos pensadores en relación al filosofar desde el punto de vista formal o de su configuración discursiva, que es el aspecto que nos interesa en este trabajo, y que si bien a lo largo del tiempo en su obra posterior fueron desagregando estos conceptos en sus distintas consecuencias, sin embargo sostuvieron intacto este punto de partida epistemológico en sus principios teóricos e intencionalidades políticas hasta sus últimos escritos. Considerando esta advertencia metodológica, finalmente, con el objeto de aportar un poco de luz sobre este problema más general que mencionamos con anterioridad, auxiliados en las visiones no siempre coincidentes de estos dos pensadores latinoamericanos imprescindibles de nuestro tiempo, extraeremos algunas conclusiones sobre lo que deba ser el filosofar en nuestro contexto.

\section{Desarrollo}

\subsection{Enrique Dussel, la filosofía como respuesta particular al problema universal}

El filósofo mendocino Enrique Dussel, quien ha hecho una titánica labor por desenmascarar la pretendida centralidad greco-latino-germánica dentro de la historia universal, anota algunas consideraciones en torno a la posibilidad de un diálogo global interfilosófico, superando la ceguera universalista y la displicencia relativista, para atender a las riquezas y carencias que las distintas tradiciones culturales pueden ofrecernos. En este afán, Dussel postula primeramente una interesante observación en torno a la naturaleza del saber filosófico.

Dussel asume como punto de partida de su trabajo, persuadido de las enseñanzas que recibió por parte de Paul Ricoeur, que pre-existen universalmente ciertos “núcleos problemáticos fundamentales" que se imponen a toda cultura y ante los cuales cada comunidad responde de manera diversa. Estos núcleos tienen que ver justamente con interrogantes que atraviesan todas las esferas de la vida de una comunidad, pero así mismo la determinan en razón de la forma según la cual dicha comunidad resuelva su sentido. Estos misterios tales como la razón del Devenir incesante del mundo, o los límites de la interioridad individual y de la libertad humana, por ejemplo, se presentan según Dussel en todas las formas culturales de nuestro mundo sin excepción y no son exclusivas de ninguna.

Así mismo las primeras respuestas ante estos "núcleos problemáticos" suelen ser de carácter mítico, lo cual no implica irracionalidad puesto que a su manera estos mitos “dan razones", que dotan a la totalidad de lo real de un sentido, es decir una pre comprensión general del cosmos. Así como estos mitos son racionales también se puede admitir su universalidad y conceptualidad, constituyen una forma particular de racionalidad que a su vez se sirve de elementos narrativos de abundante significación, o sea que pueden permanecer abiertos, por lo cual se explica que algunos de ellos tengan aún en nuestros días sentido explicativo. Esta etapa del pensar que comúnmente suele ser confinada a un mero paso previo para el advenimiento del Lógos, o 
discurso racional propiamente filosófico, es identificada por Dussel como una auténtica filosofía, o sabiduría, que piensa la totalidad, la comprende y da razones de la misma, más no naturalmente con el dispositivo lógico que acostumbramos a llamar científico:

En su sentido histórico, los «amantes de los mitos» eran también y estrictamente «amantes de la sabiduría», y por ello los que posteriormente serán llamados filósofos deberían más bien ser denominados filo-lógos, si por lógos se entiende el discurso racional con categorías filosóficas (Dussel, 2009, p. 97).

Posteriormente a esta etapa de producción de mitos, que se dio de manera paralela y diferente en todos los confines del globo, comienza un singular proceso de reducción de las ambigüedades conceptuales del mito hacia la univocidad de ciertos términos y la progresión metódica de las narrativas, lo que hoy identificamos con categorización conceptual filosófica. Este proceso no es independiente de la cosmovisión mítica, sino que se enmarca comprensivamente en ella. En este proceso se sacrifica, naturalmente, la riqueza simbólica del Mito en aras de la precisión conceptual del discurso filosófico. Sin embargo, las conclusiones ontológicas fundamentales y ciertos elementos explicativos de los relatos míticos no están del todo ausentes de las narraciones filosóficas, sino que subsisten solapadamente en estas nuevas formas de explicación de lo real, ejemplos de esta presencia son la idea de la inmortalidad del alma o la creación ex nihilo. No obstante, si bien estos elementos míticos no desaparecen nunca del todo, (como es bastante evidente en los diálogos platónicos que tenemos por filosóficos), en esta etapa solamente se los utiliza conscientemente a modo ilustrativo, ejemplar, pero no por su valor propio, sino para ser interpretados a través de la Filosofía. Aludiendo a esta reducción semántica que caracteriza el nacimiento de la Filosofía propiamente dicha nos explica Dussel:

\begin{abstract}
Nos tienen acostumbrados, en referencia al pasaje del mythos al lógos, de ser como un salto que parte de lo irracional y alcanza lo racional; de lo empírico concreto a lo universal; de lo sensible a lo conceptual. Esto es falso. Dicho pasaje se cumple de una narrativa con un cierto grado de racionalidad a otro discurso con un nivel distinto de racionalidad. Es un progreso en la precisión unívoca, en la claridad semántica, en la simplicidad, en la fuerza conclusiva de la fundamentación, pero es una pérdida de los sentidos del símbolo que pueden ser hermenéuticamente redescubiertos en momentos y lugares diversos (característica propia de la narrativa racional mítica). Los mitos prometéico o adámico siguen teniendo todavía significación ética en el presente (Ricœur, 1963). Entonces el discurso racional unívoco o con categorías filosóficas que puede, de alguna manera, definir su contenido conceptual sin recurrir al símbolo (como el mito), gana en precisión, pero pierde en sugestión de sentido (Dussel, 2009, p. 96).
\end{abstract}

Avanzando luego con una exhaustiva enumeración de producciones que se han desarrollado de manera independiente en las distintas culturas y pueblos del planeta y llamativamente semejantes en lo que refiere a sus estructuras categoriales conceptuales, Dussel deja en evidencia el profundo grado de ignorancia que conlleva identificar al pensamiento griego y su posterior evolución por la línea romana, cristiana y germánica con lo que debe ser llamado como la única y estricta Filosofía. No existe evidencia razonable que indique que el pensamiento griego sobresalga o se distinga frente a otras producciones culturales paralelas, de hecho, como muchas otras veces 
en la Historia, la supuesta "superioridad" es una construcción forzosa fundada en la situación de dominio parasitario mediante el cual los países centrales someten a los países periféricos, confinando así su desarrollo cultural a la alienación y la reproducción. En base a esto podemos dar por tierra con el lugar común, que considera la aparición de la Filosofía como el "milagro griego".

En resumidas cuentas, Dussel dice que la Filosofía se refiere al modo general que han ido encontrado las distintas culturas desde sus orígenes hasta nuestros tiempos de enfrentar comprensivamente ciertos "núcleos problemáticos fundamentales" que son comunes a toda la humanidad. Esta comprensión y el modo de articularla conceptualmente fue transformando sus elementos narrativos y concentrando su riqueza semántica desde la racionalidad mítica hacia la racionalidad lógica, sin ser ninguna más o menos filosófica, en el sentido de que las dos ordenaron una comprensión del mundo a través de una sabiduría y una tensión desinteresada hacia ella.

Por último, podemos establecer las pautas principales que establece nuestro autor en torno a la naturaleza y fisionomía del pensamiento filosófico en sentido estricto. El mismo se funda primeramente en el uso unívoco y preciso de ciertas palabras, su claridad semántica, y la simplicidad en el desarrollo y la exposición de los enunciados que conforman. Por otro lado, puede decirse que la Filosofía trabaja con un grado de abstracción que le permite separar el contenido simbólico de los fenómenos concretos, para dotar a sus proposiciones de carácter universalizable. Finalmente, una proyección analítica y ya no sintética de los fenómenos, y cierta prescripción metodológica para avanzar sobre la comprensión de lo real en base a los conceptos, son las notas distintivas que nos permiten establecer un criterio de demarcación entre las narraciones míticas y las filosóficas, superando así la típica oposición reduccionista: irracional-racional, particular-universal y concreto-conceptual.

Esta estructura categorial conceptual, como muestra el trabajo de Dussel, no es propia del pensar griego, sino que se ha dado en cada una de las culturas que poblaron el orbe. Y es justamente por esta dirección del meditar humano hacia un meollo común que podemos pretender un diálogo interfilosófico, sobre la base de un conocimiento desprejuiciado de las virtudes y los vicios de los distintos modos de respuesta a los problemas, que han producido las diversas culturas. Cabe destacar aquí que, si bien el autor abre la posibilidad de universalidad de todo discurso filosófico y su consiguiente capacidad para dialogar interculturalmente, no por eso deja de admitir el carácter histórico y políticamente situado de las respuestas dadas a los núcleos problemáticos fundamentales. En efecto, el olvido de este carácter situado de las producciones filosóficas es lo que ha propiciado la universalización ideológica de una cultura geopolíticamente dominante sobre el resto.

\subsection{Arturo Roig y la Filosofía como Crítica Normativa}

Arturo Andrés Roig es una figura que transita sin idealismos ni dogmatismos entre la Historia y la Filosofía, meritorio cultor y fundador de la Historia de las Ideas, trata con su labor de reconciliar estos dos ámbitos del saber para posicionar las diversas producciones discursivas de una cultura en su justo lugar como parte de una tensión histórica de implicancias sociopolíticas. Si bien 
Roig ha rehusado siempre caer en definiciones esencialistas y ahistóricas, en la Introducción de su obra Teoría y Crítica del Pensamiento Latinoamericano nos da algunas claves ineludibles para entender la justificación y la misión del pensar filosófico y su peculiaridad latinoamericana.

Roig abre su texto advirtiendo que la Filosofía se ha determinado siempre como un saber que se coloca un paso atrás de sí mismo para juzgarse y conocer sus propias limitaciones, este carácter crítico existe incluso desde antes de la aparición de la filosofía kantiana, con la cual, como es sabido, esta tendencia se consolida y ordena. Pero esa crítica preeminentemente gnoseológica, propia del pensar kantiano, no agota la totalidad de la crítica filosófica, la misma toma en cuenta también al sujeto que produce tal conocimiento, sus circunstancias y condiciones. La Filosofía se presenta entonces como un saber crítico, que se cuestiona a sí mismo, pero también al sujeto particular que porta tal saber, y es allí donde reside su peculiaridad.

Siguiendo esta línea argumental Roig considera el tema del comienzo del filosofar a partir de una primera dimensión que es netamente axiológica y que pertenece al sujeto que filosofa en cuanto tal. La misma consiste en la necesidad de este sujeto de ponerse a sí mismo en valor y poner en valor el hecho mismo de pensarse. Este ponerse a sí mismo como valioso es la condición a partir de la cual se da el comienzo de todo filosofar auténtico, puesto que nadie puede pensarse si antes no ha considerado como valiosa su existencia y la comprensión de la misma. Esta categoría normativa que denomina "a priori antropológico", puede avizorarse someramente según Roig en la propia filosofía kantiana, pero aparece de manera más patente, aunque en otro sentido distinto al dado por el autor, en la obra de Hegel. Lo interesante es que opera en ella, tal vez a pesar del propio Hegel, un rescate de la circunstancialidad concreta de los individuos, es decir la patencia de su aquí y ahora, que al ser tenidos por valiosos se vuelven pauta ineludible de todo el posterior filosofar. Entonces esta normatividad o pauta antropológica como la plantea Hegel de "tenerse a sí mismo como valioso absolutamente" es anterior y a su vez condición de posibilidad de toda normatividad lógica o gnoseológica en el sentido kantiano que pueda desarrollar posteriormente la Filosofía.

Un problema que emana inmediatamente de este a priori es el del sujeto que ejerce esta autovaloración y el consiguiente comienzo del filosofar que propicia. Naturalmente no estamos aquí considerando a un sujeto individual, a la manera del solipsismo cartesiano, sino colectivo, es decir no un yo, sino un "nosotros". Pero este nosotros tampoco es una categoría resuelta, evidente y absoluta, sino que es una construcción histórica en la cual se manifiestan las naturales tensiones de intereses particulares de una comunidad. Sin embargo, no por ello se deja de identificar el nosotros con una unidad común dada por un pasado digno de ser salvado y un horizonte utópico, como postulado rector de las acciones de esa determinada comunidad o grupo humano. Así esta pauta fundadora de la Filosofía no es tanto un tenerse a sí mismo como valioso, sino más propiamente un tenernos a nosotros mismos por valiosos y dignos de ser pensados en nuestras circunstancias concretas e históricas.

Así en Roig el sujeto que filosofa es aquel que ha asumido su valor dentro de un colectivo, y tal valor no es abstracto, sino que parte de la consideración más elemental de su cotidianidad y su temporalidad concreta y particular, situada. En el caso de nuestro contexto latinoamericano, signado por la situación de dominación y sometimiento a los centros de poder, tal valerse a sí mismo desemboca ineludiblemente en el descubrimiento de una necesidad de liberación 
de estas condiciones de opresión. Es decir, nuestra Filosofía si se quiere auténtica, deberá ser necesariamente una Filosofía que denote la situación de dominación y pretenda revertirla, transformando así la realidad que nos toca.

Trataremos de apuntar ahora brevemente las razones por las cuales para Roig la Filosofía es una práctica o "saber de vida” y, como tal, naturalmente indisociable del factor ético y político. Estas valoraciones no se dan pues en la Filosofía como un agregado que se pueda deducir de una verdad contemplativa, sino a la inversa como la condición misma de su desarrollo, puesto que en la Filosofía no se puede separar el camino (lo que sería la normatividad axiológica) de lo descubierto (cualquier forma de normatividad lógica deducida del a priori). Por tanto, la normatividad de la Filosofía para Roig es una condición incita al mismo filosofar. Tal normatividad se muestra por vez primera, como también mostró Hegel, en la resolución que da comienzo a la Filosofía, es decir en el "a priori antropológico". Cuando el sujeto pensante se asume a sí mismo y su situación peculiar como absolutamente valiosas, se desata lo que funciona luego como puntapié inicial de su construcción comprensiva del mundo. En razón de esto puede vislumbrarse la distancia entre nuestro autor y la tradición filosófica que concibe al filosofar como un saber meramente teorético o contemplativo, cuya normatividad se pretende externa al filosofar mismo y no su punto de partida. Lo dicho acerca de la práctica de la filosofía como un "saber de vida" desemboca necesariamente en un pensar consciente en y para nuestras circunstancias y necesidades, justamente lo que se propuso, sin ir más lejos, en la generación de intelectuales del 37, pionera del pensamiento filosófico en América.

Es interesante llamar la atención ahora acerca de la unidad indisoluble entre el sujeto del filosofar y su discurso. Así como nuestra situación al ser descubierta como valiosa determina programáticamente todo posterior filosofar, cuando se da el caso contrario a la reproducción simiesca de lo foráneo o la coronación exclusiva de la tradición filosófica imperante, con más o menos consciencia de ello, se desarrolla un modo de Filosofía cuyo origen axiológico puede ser detectado en el análisis de su discurso. Esto sucede en razón de la naturaleza inherentemente discursiva de los seres humanos, a partir de la cual se abre y expresa ineludiblemente su comprensión del mundo, la cual, como dijimos, parte de una valoración específica más o menos consciente.

Entonces atendiendo a los discursos que circulan en nuestros contextos podemos extraer conclusiones en torno al nivel de incidencia que en ellos imprime el a priori antropológico y con él, al grado de autenticidad de tal filosofar. Pero esta relectura que produce Roig en torno a los discursos no es excluyente de las narraciones filosóficas, sino que todo discurso a su manera expresa una determinada posición axiológica, una determinada normatividad ética y política que se inscribe en una específica coyuntura y que puede ser leída en clave emancipatoria o de dominación. Con esto Roig amplía inconmensurablemente la riqueza del ámbito de pensamiento e interés de la Filosofía, que puede brindar las herramientas teóricas elementales para el análisis, pero que se capitaliza efectivamente con la Historia de las Ideas, como un saber forjado para la liberación.

La normatividad del pensar filosófico, tema central de este texto, es establecida por Roig finalmente sobre cuatro pautas que en rigor no responden ni a momentos ni a etapas de aparición, sino que se entrelazan y se suponen entre sí. La primera ya mencionada con insistencia consiste entonces 
en la autoafirmación del sujeto como valioso, y lleva por consecuencia a la segunda: reconocer al otro como sujeto, en el sentido de reconocerle historicidad. Luego, se hace esencial determinar la legitimidad de esta valoración, lo que implica necesariamente organizar mediante el discurso nuestra posición axiológica. En último lugar, emana de estas exigencias la necesidad de gestar un saber para la liberación, del cual la Filosofía establecerá las bases teóricas, pero que no se agotará en ella. En el caso concreto latinoamericano, este saber debe partir del reconocimiento de nuestra situación de dominación y colonialidad.

En resumidas cuentas, para Roig la Filosofía como saber crítico posee una serie de pautas o normatividad, no a la manera de agregado contingente, sino de condiciones posibilitadoras de su existencia, las mismas se basan en el "a priori antropológico", es decir la valoración del propio sujeto como actor de la Historia y no como mero espectador pasivo. Luego de este reconocimiento se desprende el reconocimiento del otro en su historicidad, con la justificación de esta valoración, la puesta en marcha de un aparato discursivo donde se organice esta posición axiológica y finalmente la gestación de un saber para la liberación. Estos principios son los que debería seguir un saber filosófico consciente y desalienado en nuestros contextos latinoamericanos.

Para concluir hay que señalar otro rasgo central que emana del valor programático de la pauta señalada por el "a priori antropológico" y que distingue a nuestra Filosofía de la tradición europeizante ya señalada. El mismo tiene que ver con el carácter "auroral" de este saber consciente de su propio valor, es decir que tiene la misión de señalar un nuevo amanecer histórico:

(...) el valor de pauta que posee toda norma que funcione como a priori antropológico, se encuentra sin duda una comprensión de la filosofía como saber auroral y no como saber vespertino, por lo mismo que no es necesario esperar una “decadencia" para experimentar formas rupturales (Roig, 2009, p. 15).

Esta idea es el opuesto directo de la típica imagen retórica hegeliana que describía la visión tradicional de la relación entre la Filosofía y la Historia como un saber de lo acaecido, "el búho de Minerva echa vuelo al caer el crepúsculo" (Hegel, 1968, 37). Así el pensamiento de Roig nos invita a pensar el ejercicio de la Filosofía no como una justificación del pasado y de la tradición sino como una posibilidad proyectada hacia el futuro, una oportunidad de soñarnos mejor.

\subsection{Filosofía Latinoamericana: entre la tensión comprensora y la vigilancia normativa}

Hasta aquí hemos intentado exponer las nociones más importantes que pudimos vislumbrar en los textos elegidos acerca de lo que cada autor considera como lo propio de la Filosofía. A continuación, entonces nos toca poner en diálogo estas dos concepciones para encontrar distancias y puntos de contacto entre ellas, en base a citas concretas extraídas de los textos trabajados.

En primer lugar, podemos decir que tanto Dussel como Roig proponen corregir en sus respectivos trabajos el vicio común de identificar el pensar filosófico con una tradición y un 
cultivo específico del mismo. Justamente esta tradición es la construida y perpetuada desde los centros de poder del mundo, que a la vez que des-historizan el acto mismo de comprenderse, constriñen las posibilidades de atender, responder y actuar ante los problemas esenciales de la humanidad, a una sola forma específica de comprensión. Así Dussel después de una exhaustiva enumeración de producciones filosóficas chinas, indostánicas, hinduistas y otras de igual constitución estructural, conceptual y categorial que la encumbrada filosofía griega, concluye:

Con esto queremos indicar claramente que ni la Filosofía nació sólo ni primeramente en Grecia (en el tiempo), ni puede tomársela como el prototipo del discurso filosófico (por su contenido). De allí el error de muchos que en vez de describir los caracteres que deben definirse como criterios de demarcación entre el mito y el discurso categorial filosófico, tienden a tomar a la filosofía griega como la definición misma de la Filosofía en cuanto tal. Esto es confundir la parte con el todo: un caso particular no incluye la definición universal (Dussel, 2009, p. 99).

Podemos ver entonces que Dussel entiende la Filosofía en un sentido más amplio que el simple discurso racional divorciado de la racionalidad mítica. Para él la Filosofía, en tanto sabiduría y tensión hacia la sabiduría, preexiste a la ordenación estricta que la totalidad de las culturas comenzaron a establecer como pensamiento propiamente filosófico. Incluso si admitimos que solamente esta última forma de racionalidad que delimita la riqueza semántica ofrendada por los mitos es la verdadera filosofía, no podemos afirmar sin más que la misma sea excluyente del mundo griego, como se suele presentar. Entonces esta pluralidad de voces y comprensiones de rasgos netamente filosóficos pueden introducirse en un fructífero diálogo e intercambio con el objeto de superar la autoridad greco-latino-germánica impuesta por la modernidad y comenzar a dirigir nuestros pasos hacia una superación de la modernidad eurocéntrica que democratice la interpretación de los núcleos problemáticos fundamentales.

Desde este punto de vista, hacer Filosofía en nuestros contextos implicaría responder desde nuestra particularidad a los problemas universalmente presentes y a partir de nuestra respuesta particular construir un diálogo de pretensiones globales, partiendo del conocimiento y el reconocimiento de las respuestas que las distintas culturas han construido para enfrentar estos problemas que, en cuanto humanos, son universales.

Roig por su parte cuestiona a esta misma tradición europeizante, aunque ya no en el mismo sentido que su compatriota, sino a partir de las situaciones de dominación y explotación que en su fingida primacía ocultan, y sobre todo por la falta de autenticidad y consiguiente ideologización que se deriva del olvido de su a priori antropológico, es decir el olvido de su empiricidad concreta. Al partir de una caracterización de la Filosofía como pensar crítico, cuya problematización se da no solamente en el ámbito de su ejercicio y sus límites epistemológicos sino en razón del sujeto que filosofa, puede Roig postular el comienzo de todo filosofar en una actitud axiológica de afirmación del valor del propio sujeto del filosofar y su situación concreta y por lo tanto, puede desde su análisis establecer también criterios de legitimidad de estas autoafirmaciones, atendiendo justamente a las situaciones socio-políticas concretas que, solapadamente o no, finalmente reivindican. Al respecto nos dice Roig: 
Ciertamente que en los griegos se encuentran los antecedentes de la tendencia que conducirá a reducir aquel "poner" a una función noética, sobre la cual se pretenderá justificar más adelante un "sujeto trascendental". El a priori antropológico, en cuanto es fundamentalmente un "ponerse", exige el rescate de la cotidianidad, dentro de los marcos de esta última y es función contingente y no necesaria. En contra de Hegel mismo, en quien el sujeto histórico corre el riesgo permanente de disolverse en un mítico sujeto absoluto, que se hace cargo en última instancia de todo comienzo posible del filosofar y en contra de la "tética noética" husserliana, aquel sujeto está eximido de las exigencias de cualquier "morale par provision" de cualquier "determinabilidad" que no sea la suya propia, o de cualquier "epojé" que lo saque de su vida cotidiana. El a priori antropológico es el acto de un sujeto empírico para el cual su temporalidad no se funda, ni en el movimiento del concepto, ni en el desplazamiento lógico de una esencia a otra (Roig, 2009, p. 12).

Así en virtud de estos moldes tradicionales y excluyentes que ocultan su origen concreto, la Filosofía eurocéntrica no sólo se autoproclama como portadora de la única sabiduría, sino que se construye como la justificación de una situación de dominación signada por un ejercicio de dicotomización epistemológica entre los discursos que son dignos de ser tenidos en cuenta y los que no, lo que comúnmente se concibe como Verdad y Dóxa, y que por su propia constitución lógica clausura y niega la posibilidad de verdad en la variedad de los discursos particulares frente a la univocidad absoluta de la palabra filosófica. Dicotomización que en los ámbitos políticos participativos confronta directamente contra los ideales propiamente democráticos de las sociedades modernas.

Retomando nuevamente esta última noción que se desprende del texto de Roig y su contundente rescate de la carnalidad del sujeto filosofante, su situación y sus circunstancias históricas concretas, como determinantes de su posterior filosofar, podemos hallar otro punto de contacto, aunque con matices distintos, con el trabajo de Dussel. Este último, nos invita a construir un diálogo mundial interfilosófico, en base a ciertos principios formales y materiales que pueden tenerse por universales, pero no por ello divorciados de la cultura particular en la cual fueron gestados. Así, por ejemplo, la igualdad de condiciones para el diálogo, propuesta por el filósofo alemán Apel en sus trabajos de los años 70, donde introduce la idea que un discurso argumentativo para ser válido debe otorgar a su contraparte igualdad de condiciones para la discusión, claramente puede ser un principio formal universal que todos aceptemos como valioso, y no por ello menos históricamente situado y fruto de una cultura particular. Así mismo, el hecho de afirmar la preminencia de las condiciones materiales de vida universalmente válidas como tener un cuerpo viviente que padece necesidades y necesita reproducir sus condiciones de existencia, como punto de partida necesario para valorar la justicia de un determinado sistema político, tal como lo vislumbró Marx a lo largo de su obra, puede tenerse también como otro principio universal, aunque esta vez material y no formal. En este sentido Dussel afirma criterios universales, pero sin necesidad de negar su origen cultural específico, con lo cual de cierta forma se rescata un filosofar situado: 
Una Filosofía absolutamente post-convencional es imposible (sin ninguna relación a una cultura concreta), y todas las filosofías, situadas inevitablemente en alguna cultura, pueden sin embargo dialogar con las obras a través de los «núcleos problemáticos» comunes y las respuestas de los discursos categoriales filosóficos, en cuanto humanos, y por ello universales (Dussel, 2009, p. 104).

En Roig, como ya habíamos anticipado podemos ver también un hincapié particular en la historicidad del pensar filosófico, pero ya no como un mero carácter o rasgo de origen a tener en cuenta en vistas a un diálogo de pretensiones mundiales a la manera que lo presenta Dussel, sino como la condición estructural de su existencia y más aún como el parámetro de su legitimidad. Sabemos que el a priori antropológico es la normatividad axiológica fundacional del pensar filosófico y que implica a la vez que la afirmación del sujeto, la de su situación concreta, es decir la asunción de la situación contextual en cuanto tal como condición de la Filosofía. Y la preponderancia de esta estructura es la que determina los niveles discursivos de su expresión, como dice el mismo Roig:

Más aún, podríamos decir que la normatividad del a priori antropológico condiciona toda otra forma posible de normatividad, aun las que se puedan establecer para el pensamiento lógico en relación con el problema de la naturaleza del sujeto (Roig, 2009, p. 9).

La pérdida del reconocimiento de esta situación del a priori, volvería al pensamiento ideológico, en el sentido que el mismo ocultaría mediante los artilugios más o menos persuasivos de su discurso, enmarcado quizás en categorías tales como "necesidad", “universalidad”, “objetividad”, la condición sociohistórica específica que lo gestó y que de cierta manera sostiene. Toda objetividad esta sostenida entonces en una específica sujetividad.

Podemos pensar entonces que el a priori antropológico es condición necesaria pero no suficiente para un pensar auténtico y emancipador. Es decir, todos los discursos se construyen a partir de una autovaloración más o menos consciente de un determinado "nosotros" que los sostiene y estructura, pero el hecho de olvidar o no evidenciar este carácter fundador ideologiza el discurso en el sentido de que el mismo puede pasar por avalorativo y por tanto "libre" de prejuicios y proclive de ser reproducido y circular así de manera acrítica.

Es en base a esto por lo que nos sentimos tentados a pensar que el diálogo interfilosófico mundial que Dussel propone no puede ser librado simplemente tomando de cada discurso cultural los elementos que nos resulten útiles y favorables de compartir con otras culturas distintas. Según parece, los discursos no son meras herramientas indiferentes, sino que implican de suyo valoraciones ideológicas, es decir que toman partido por algo. Entonces, si bien la igualdad de condiciones para el diálogo de Apel nos puede parecer un criterio razonable y universalizable, habría que establecer las circunstancias y coyunturas en las cuales tal discurso fue gestado y qué intereses ideológicos y de clase sustenta en cada momento sociopolítico concreto. Lo mismo puede suceder con el principio material de Marx, que nadie puede objetar, pero tampoco por ello sacralizarlo y trastocarlo en eternidad. En este sentido nos dice Roig, 
Los verdaderos alcances de la crítica únicamente podrán señalarse, por lo dicho, en la medida en que se tenga en cuenta la presencia de lo axiológico, a tal extremo de que no hay una "crítica de la razón" que pueda ser ajena a una "crítica del sujeto", desde cuya sujetividad se constituye toda objetividad posible (Roig, 2009, p. 9).

No queremos dejar pasar en este lugar otro rasgo determinante en el cual nuestros pensadores se encuentran y que tiene que ver con el ya extensamente mencionado a priori antropológico de Roig. También Dussel en su texto rescata este rasgo fundante de la Filosofía como posibilidad de revertir el más que vigente eurocentrismo, aunque sin darle el desarrollo conceptual que le da Roig reconoce la necesidad de una valoración de lo propio como condición de posibilidad del filosofar y del consiguiente diálogo interfilosófico. De esta manera hablando justamente de cómo el eurocentrismo se postuló como el portador de la verdad universal, al tiempo que en el ámbito geopolítico extendía su etnocentrismo con dimensiones globales inéditas, Dussel, nos conmina a ponerle un freno a tal avasallamiento en la valoración de lo nuestro diciendo que "esa pretensión termina cuando los filósofos de las otras tradiciones filosófico-culturales toman conciencia de su propia historia filosófica, y del valor situado de las mismas” (Dussel, 2009, p. 103).

Finalmente queríamos cerrar esta confrontación haciendo una pequeña mención a un tema que nos parece central y que tiene que ver con la programática o proyecto filosófico al que nos conduce en cada caso la crítica a la tradición filosófica hegemónica perpetrada por estos dos pensadores. Así vemos como en Dussel esa delimitación específica que forja acerca de lo que es la Filosofía, como un saber unívoco, claro, simple, abstracto, analítico y metódico, que hunde sus raíces en la sabiduría mítica, lo lleva a producir justamente una Historia de la Filosofía ampliada, que tiene resonancias inclusive en proyectos específicos de planes de estudio académicos. En ellos muestra como la enseñanza de la Filosofía tendría que ser dada a partir de cortes temporales horizontales que incluyan por ejemplo en el caso de los "primeros grandes filósofos de la humanidad" o etapa inicial del filosofar, "donde serían expuestos las filósofas y filósofos que produjeron las categorías germinales filosóficas en Egipto (africano), en Mesopotamia (incluyendo los profetas de Israel), en Grecia, en India, en China, en Meso-américa o entre los Incas" (Dussel, 2009, p. 105), dando cuenta justamente de esta ampliación inclusiva que mencionamos frente a la empobrecedora hegemonía de la línea greco-latino-germánica.

El caso de Roig es distinto y se da conforme al descubrimiento de la estructuración normativa eminentemente axiológica del pensar filosófico, fundado como vimos en el a priori como acto de autovaloración de los pueblos. Este a priori no es propio y exclusivo de los discursos típicamente filosóficos, sino que opera como muestra Roig, en todas las esferas de la praxis humana, desde los saberes populares hasta las artes, desde el periodismo político hasta las ciencias exactas, todos los discursos están signados por la afirmación de un nosotros, que se debate en las tensiones sociopolíticas de una época. Entonces lo que Roig busca, y en esto reside la importancia de las Historia de las Ideas en su desarrollo intelectual, es situar justamente el foco del pensamiento en el rasgo axiológico de los discursos, y de allí que su interés exceda y extralimite las producciones englobadas comúnmente bajo la categoría de Filosofía, puesto que las mismas suelen muchas veces reproducir acríticamente criterios ideologizados. Roig, a diferencia de Dussel, no quiere 
exclusivamente ampliar la Historia de la Filosofía, sino potenciar la riqueza filosófica de todas las producciones discursivas de una comunidad cultural. En vistas a este objetivo, se expresa diciendo que:

\begin{abstract}
Por esto mismo se hace necesario estudiar de qué manera el sujeto americano ha ejercido aquellas pautas, como también el grado de conciencia que ha adquirido de las mismas. Para esto, la historia de las ideas constituye un campo de investigación más lleno de posibilidades que la tradicional "historia de la filosofía". En efecto, la afirmación del sujeto, que conlleva una respuesta antropológica y a la vez una comprensión de lo histórico y de la historicidad, no requiere necesariamente la forma del discurso filosófico tradicional (Roig, 2009, p. 18).
\end{abstract}

\title{
4. Conclusión
}

Podemos afirmar, sin temor a perder rigor conceptual, que la inquietud propia de toda comunidad humana de ordenar su universo bajo la directriz de un sentido que signifique su tránsito por el mundo no es privativa de ninguna cultura específica, como ya oportunamente lo señaló Dussel, y así mismo implica una valoración de lo propio y una mirada crítica, como explica Roig. Según el relato paradigmático, fue Pitágoras, un filósofo nacido en la isla de Samos, inscripto en la antigua tradición griega, quien acuñó el término "filósofo" no solo para diferenciarse de la sabiduría erudita y acumulativa que ostentaban otros tipos de sabios, sino sobre todo por el sentido crítico y siempre abierto de su búsqueda intelectual. Pese a este origen cultural estricto, podemos argüir que, si bien toda nominación es ineludiblemente parcialista y a la vez que crea una realidad en el nombre, cercena en ella otras posibilidades, nosotros, como seres humanos, no tenemos más opción que elegir una parcialidad para construir sentidos socialmente aceptables. En este caso, nos resignamos al nombre Filosofía, para denominar esa tensión inherentemente humana hacia el saber, que ha aparecido a lo largo de la Historia de las más variadas formas y en muy distintas civilizaciones y que hoy construimos bajo el sello y el compromiso latinoamericano.

Sin duda el profundizado error de identificar la línea greco-latino-germánica con la única y estricta Filosofía, también nos obliga a llamar la atención sobre este término tan cargado de un sentido ajustadamente europeizante, ya que tal impropiedad si bien se encuentra bien superada en los debates académicos, está como todo discurso en constante disputa en el campo de batalla de nuestras prácticas y decisiones políticas. Con este objeto hemos puesto en juego estas recreaciones y traducciones apropiadoras que tanto Dussel como Roig hacen del antiguo término "Filosofía”, su estructuración y su destino. Igualmente, no queremos dejar de alertar e insistir en esto de que no es inocente el uso de las palabras, puesto que las mismas autorizan mudamente tradiciones y supuestos peligrosamente alienantes. Practicar el ejercicio de la Filosofía como una vigilancia normativa a la manera de Roig y una vuelta a la consideración de su origen comprensoramente abierto como señala Dussel, nos posibilitarían no caer en un olvido que no es otro que el olvido de nuestro propio valor como protagonistas y creadores de nuestra liberación históricamente situada. Es importante por ello hacer notar aquí la radical diferencia entre este sujeto filosofante empírico abrazado a su cotidianidad y determinado por una temporalidad tal cual lo postula Arturo Roig, frente a ese otro sujeto del filosofar de la tradición europeizante, de la cual destacamos los hitos de Parménides y Hegel, en la cual la Filosofía no respondía a otra determinación y exigencia que la dada por un pensar puro, 
abstracto y ahistórico, y en eso radicaba su libertad, aunque solapando ideológicamente en esa pretensión las circunstancias socio-políticas que sostenían al sujeto reflexivo.

Finalmente, más allá de las distancias mencionadas y los intereses puntuales de cada filósofo, más allá de los lugares en que cada uno se sitúa y los pormenores de sendas teorías, nos parece imprescindible y central destacar que hay en ambos una superación de la falsa dicotomía entre teoría y práxis, que cierta tradición supo sostener como instancias separadas, identificando la primera con lo estrictamente intelectual y avalorativo, y la segunda con la participación en los asuntos del mundo. Esta errónea dicotomía muestra su falsedad cuando analizamos los hechos a la luz del historicismo propuesto por ambos autores, según el cual todo discurso surge y está atravesado por un contexto particular. Así nos damos cuenta de que cada pensamiento, cada idea, cada conjetura que podamos hacer sobre la realidad supone una determinada afirmación axiológica que toma partido y justifica un determinado estado de cosas. Ya sea una apreciación histórica, una nota periodística, un ensayo filosófico y hasta un estudio científico, todos a su manera parten de los límites y las determinaciones de una situación histórico-cultural concreta que los ordena y legitima. Entonces afirmar que la teoría puede ser producida desatendiendo a la praxis concreta implica en sí mismo una aseveración ideológica en tanto aprobación de una praxis específica y justificación de un estado de cosas. Pero está cuestión tiene así mismo otras aristas igualmente influyentes.

Nos parece atinente aquí explayar si quiera brevemente este asunto, que por cierto da para un desarrollo más pormenorizado, haciendo hincapié en el tipo de narrativa textual que se deriva de cada uno de los modelos filosóficos contrapuestos y que se define a partir de una específica forma de comprender la verdad y por consiguiente la política. En primer lugar, una Filosofía que decide encerrarse en sí misma como gesto de libertad, desoyendo las voces del mundo o dóxa, para pronunciar un discurso enmarcado en los límites de una lógica excluyente, que se funda en principios que resisten a la diferencia y pretenden la identidad, exige una comprensión esencialista del fenómeno de la verdad, que queda así caracterizada como universal y absoluta, pero más aún como privilegio de una aristocracia espiritual que se separa de su plebe. Ya sea como una esfera inmutable al estilo parmenídeo, o como dialécticamente desenvuelta en la Historia como en Hegel, la verdad es y no puede no ser, es decir no puede someterse al arbitrio del debate público. Ahora bien, si pensamos en los tipos de discursividades que atienden nuestros autores y revindican como Filosofía, claramente está operando en ellos un principio de democratización de las voces dignas de ser tenidas en cuenta, y en ese mismo principio la construcción de una verdad, ni relativista ni arbitraria, sino fruto del consenso, es decir vigente bajo las normas que las comunidades se autoimponen o, dicho de otra forma, justificada desde el perspectivismo. Este principio discursivo no responde simplemente a una pauta humanista a ultranza, sino a criterios epistémicos como el hecho de que el mito es también, como prueba Dussel, racional, sistemático y conceptual, cual se ha pensado distintivamente la Filosofía Occidental frente a otras narrativas. Así mismo todo discurso humano que es parte de un determinado universo de sentido, implica y posee en sí la pauta moral y axiológica de la que se deriva una posición concreta frente a la coyuntura política de una época, por lo cual posee entonces valor para ser pensado filosóficamente y expresa así mismo una Filosofía como potencialmente productora de conceptos. 
Entonces nos parece importante si quiera al pasar mencionar esta relación entre la Filosofía Latinoamericana, tal cual la comprenden Dussel y Roig, y las formas de pronunciación textuales de la misma, para iluminar las opciones políticas que habilitan, naturalmente el Objetivismo no es tolerable con un modelo democrático, así como el perspectivismo no soporta tiranías y aristocracias. Esto se explica en parte si atendemos a la definición de las condiciones de posibilidad para ejercer la política que son la igualdad ante la palabra y ante la ley, para la primera es indispensable la horizontalidad del debate público en la confrontación de opiniones para que todas las voces pesen lo mismo en la balanza del intercambio de ideas, y para la segunda, claro está, no tendría sentido jerarquizar esas voces bajo ningún pretexto, porque la ley es la expresión de esas necesidades y esperanzas que conjuntamente se sentencian en la política.

En efecto, al reconocer ambos a la Filosofía como una praxis esencialmente política y ética, y cuya autenticidad se da en vistas a un horizonte futuro guiado hacia la liberación de los pueblos oprimidos, se echa por tierra para siempre la falsa idea tantas veces repetida por la tradición helenocentrista, de que el saber filosófico es un saber "inútil” y por tanto desafectado de la realidad cotidiana y las tensiones histórico-políticas. La utilidad del quehacer filosófico, hoy en nuestros contextos latinoamericanos, está dada entonces por una praxis liberadora que no puede divorciarse del conocimiento y la valoración de lo propio. Así mismo la producción de ese conocimiento no se construye desde la ociosidad intelectual o el apartamiento solitario, sino desde la participación y el compromiso político, desde un sujeto encarnado y resurgido en la multitud que lo resignifica y lo salva de la alienación, para convertirlo finalmente en el creador, codo a codo con ella, de su propia Historia.

\section{Referencias}

Acosta, Y. (2020). Un Humanismo crítico desde Nuestra América. En A. Arpini, M. Muñoz y D. Ramaglia (Ed.), Diálogos Inacabados con Roig, Filosofía Latinoamericana, Historia de las Ideas y Universidad, (pp 25-43). EDIFYL.

Alberdi, J. B. (1978). Ideas para presidir un curso de Filosofía Contemporánea. UNAM.

Alcoff, L. M. (2018). El Hegel de Coyoacán. En J. G. Gandarilla Salgado y M. Moralla (Coord.), Del Monólogo europeo al diálogo interfilosófico. Ensayos sobre Enrique Dussel y la Filosofía de la Liberación, (pp. 79-99). UNAM

Arpini, A. (2018). Función del intelectual y del ejercicio filosófico en escritos de Enrique Dussel previos al exilio (1964-1975). En J. G. Gandarilla Salgado y M. Moralla (Coord.), Del Monólogo europeo al diálogo interfilosófico. Ensayos sobre Enrique Dussel y la Filosofía de la Liberación, (pp. 25-39). UNAM.

Dussel, E. (2009). Una nueva edad en la historia de la filosofía: el diálogo mundial entre tradiciones filosóficas. En J. Rüsen y O. Kozlarek (Ed.), Humanismo en la era de la globalización. Desafíos y perspectivas, (pp. 93-109). Biblos.

Guadarrama González, P. (2018). El Humanismo práctico en la Filosofía política crítica de Enrique Dussel. En J. G. Gandarilla Salgado y M. Moralla (Coord.), Del Monólogo europeo al diálogo interfilosófico. Ensayos sobre Enrique Dussel y la Filosofía de la Liberación, (pp. 57-79). UNAM.

Guardiola Rivera, O. (2018). ¿Invertir la Ética de lo Normativo? De la Filosofía-Teología de la Liberación a la descolonización permanente. En J. G. Gandarilla Salgado y M. Moralla (Coord.), Del Monólogo europeo al diálogo interfilosófico. Ensayos sobre Enrique Dussel y la Filosofía de la Liberación, (pp. 99-123). UNAM.

Hegel, G. W. F. (1961). Introducción a la Historia de la Filosofía. Aguilar.

Hegel, G. W. F. (1968). La Filosofía del Derecho. Claridad. 
Oviedo, G. (2020). Filosofía Latinoamericana como ancilla emancipationis. Arturo Roig o la moral de la literatura filosófica emergente. En A. Arpini, M. Muñoz y D. Ramaglia (Ed.), Diálogos Inacabados con Roig, Filosofía Latinoamericana, Historia de las Ideas y Universidad, (pp 25-43). EDIFYL.

Parménides/Heráclito (1984). Fragmentos. Ediciones Orbis S.A.

Ramaglia, D. (2020). Filosofía Latinoamericana e Historia de la Ideas en la obra de Arturo Andrés Roig. Aportes a la valoración de su trayectoria biográfica e intelectual. En A. Arpini, M. Muñoz y D. Ramaglia (Ed.), Diálogos Inacabados con Roig, Filosofía Latinoamericana, Historia de las Ideas y Universidad, (pp 43-67). EDIFYL.

Roig, A. (2009). Teoría y crítica del pensamiento latinoamericano. Una Ventana.

Scannone, J. C. (2018). La Filosofía de la Liberación en la Argentina. Surgimientos, caracterización, historia y vigencia actual. En J. G. Gandarilla Salgado y M. Moralla (Coord.), Del Monólogo europeo al diálogo interfilosófico. Ensayos sobre Enrique Dussel y la Filosofía de la Liberación, (pp. 39-57). UNAM.

\section{AUTORES}

José Ernesto Bianchi. Profesor de Grado Universitario en Filosofía por la Universidad Nacional De Cuyo. Maestrando en Estudios Latinoamericanos por la misma Universidad. Se desempeña actualmente en docencia de nivel medio y superior.

Nadia Jimena Irrazabal Astudillo. Profesora de Grado Universitario en Filosofía por la Universidad Nacional De Cuyo. Maestranda en Estudios Latinoamericanos por Universidad Nacional De Cuyo. Se desempeña actualmente en docencia de nivel medio y superior.

\section{Conflicto de intereses}

Los autores declaran que no existe conflicto de interés posible.

\section{Financiamiento}

No existió asistencia financiera de partes externas al presente artículo.

\section{Agradecimientos}

